\title{
A etnografia pós-crítica como modo de pesquisar a prática pedagógica da Educação Física cultural
}

\section{RESUMO}

A etnografia tornou-se uma das formas preferidas de investigação no ambiente escolar em tempos recentes. Nos rastros de sua expansão, pesquisadores e pesquisadoras transformaram-na, atribuindo-lhe outras feições. Aqueles e aquelas que se ancoram nas contribuições da teorização pós-crítica passaram a ressignificá-la, dando vazão a novas produções. Nesse contexto, o objetivo do presente trabalho é apresentar a etnografia pós-crítica enquanto perspectiva metodológica em pesquisas que envolvem a prática pedagógica. Para tanto, reunimos os argumentos teóricos que fundamentaram o surgimento da etnografia pós-crítica no contexto investigado, relatamos alguns resultados provenientes de seu emprego durante a investigação das aulas culturalmente orientadas de Educação Física em uma escola pública municipal paulistana e, por fim, indicamos possíveis contribuições para o debate a respeito das investigações sobre a prática pedagógica.

PALAVRAS-CHAVE: Etnografia; Educação física; Teorias pós-críticas

\section{Jorge Luiz de Oliveira Junior}

Mestre

Secretaria Municipal de Educação de São Paulo,

São Paulo, Brasil

jorgejref@yahoo.com.br

https://orcid.org/0000-0003-2023-5184

\section{Marcos Garcia Neira}

Livre-Docente

Universidade de São Paulo, Departamento de Metodologia do Ensino e Educação Comparada,

São Paulo, Brasil

mgneira@usp.br

(ㄴ) https://orcid.org/0000-0003-1054-8224 


\title{
Post-critical ethnography as a way of researching the pedagogical practice of cultural Physical Education
}

\begin{abstract}
Ethnography has become one of the preferred forms of investigation in the school environment in recent times. In the way of its expansion, researchers transformed it, giving it other features. Those who are anchored in the contributions of post-critical theory began to re-signify it, giving way to new productions. In this context, the aim of this paper is to present post-critical ethnography as a methodological perspective in research involving pedagogical practice. Therefore, we get togheter the theoretical arguments that founded the emergence of post-critical ethnography in the investigated context, we report some results from it use during the investigation of cultural Physical Education classes in a public school in São Paulo and, finally, we indicate possible contributions to the debate about research on pedagogical practice.
\end{abstract}

KEYWORDS: Ethnography; Physical education; Postcritical theory

\section{La etnografía poscrítica como forma de investigar la práctica pedagógica de la Educación Física cultural}

\section{RESUMEN}

La etnografía se ha convertido en una de las formas de investigación preferidas en el ámbito escolar en los últimos tiempos. En el camino de su expansión, investigadores lo transformaron, dándole otras características. Quienes están anclados en los aportes de la teorización poscrítica comenzaron a darle un nuevo significado, dando paso a nuevas producciones. En este contexto, el objetivo de este trabajo es presentar la etnografía poscrítica como una perspectiva metodológica en la investigación que involucra la práctica pedagógica. Por lo tanto, recogemos los argumentos teóricos que fundaron el surgimiento de la etnografía poscrítica en el contexto investigado, reportamos algunos resultados de su uso durante la investigación de clases de Educación Física de orientación cultural en una escuela pública de São Paulo y, finalmente, indicamos posibles aportes al debate sobre la investigación sobre la práctica pedagógica.

PALABRAS-CLAVE: Etnografía; Educación física; Teorías poscríticas 


\section{CAMINHOS DA ETNOGRAFIA EM EDUCAÇÃO}

Nas três últimas décadas a etnografia conquistou um espaço privilegiado na pesquisa educacional. Bueno (2007) explica que a etnografia da prática escolar surge nos anos 1960, especialmente na Inglaterra e nos Estados Unidos, sendo paulatinamente adotada nos estudos sobre a escola e o processo de escolarização, em função da sua adaptabilidade às diferentes questões presentes em sala de aula. O crescente interesse da comunidade científica pela etnografia deveu-se aos recursos que ela disponibiliza para investigar as atividades didáticas e os processos de avaliação. Até então, os estudos sobre a sala de aula empregavam instrumentos de observação com a finalidade de registrar e analisar atitudes comportamentais de docentes e discentes em situações específicas de interação.

Em linhas gerais, a etnografia pressupõe a ida e permanência no campo de investigação por tempo suficiente, a realização de entrevistas com participantes da pesquisa e análise de documentos relacionados ao objeto de estudo. Isso faz com que a etnografia, conforme já apontava Geertz (1989), seja interpretativa, no sentido de buscar nos discursos sociais formas pesquisáveis para compreensão do objeto investigado, e microscópica, isto é, que atua num contexto bastante específico.

No ambiente pedagógico, a partir do momento em que etnógrafos e etnógrafas consideram a multiplicidade de significados em circulação, o foco passa a ser a análise do conjunto em sua relação dinâmica, postura que se faz acompanhar de uma atitude aberta e flexível no decorrer do processo investigativo. Essas possibilidades tornam a etnografia uma perspectiva teóricometodológica (PEIRANO, 2014), uma vez que permite que pesquisadores e pesquisadoras problematizem a teoria com base nos dados produzidos e vice-versa, dando fluência à produção de novos conhecimentos, como também impede que ela seja deturpada e se reduza a uma simples técnica de coleta de dados, comumente nomeada como pesquisas "do tipo", "de caráter", "de cunho" etnográfico (OLIVEIRA, 2013).

Também nas últimas três décadas, a pesquisa educacional, principalmente o campo dos estudos curriculares, sofreu influências das teorias pós-críticas. O conhecido trabalho de Paraíso (2004) detectara esse movimento já nos anos iniciais do século XXI. Segundo a autora (PARAÍSO, 2014), as pesquisas educacionais pautadas pelas teorias pós-críticas questionam alguns elementos tradicionalmente presentes no universo da pesquisa acadêmica: o sujeito racional, as metanarrativas, as causas universais, a linearidade histórica, a noção de progresso e a visão "natural" e realista de conhecimento. 
$\mathrm{Na}$ esteira desses questionamentos, a etnografia também sofreu ressignificações, justamente porque cada contexto exige demandas específicas de pesquisa com relação ao objeto de estudo e aos propósitos da investigação. Sales (2014), por exemplo, utilizou a netnografia, que consistiu em analisar um ambiente bem específico, o ciberespaço, de maneira séria e comprometida, para além da mera visualização, enquanto Balestrin e Soares (2014) adotaram a etnografia de tela voltado para o estudo de textos presentes nas mídias e contou com observação sistemática, o mergulho profundo no ambiente investigado, a entrevista com especialistas na área e o registro em diário de campo.

$\mathrm{Na}$ área da Educação Física, embora a constante adoção da etnografia nas pesquisas tenha apresentado, em alguns trabalhos, certos descompassos como a simples descrição das observações realizadas ou a mera aplicação de uma série de técnicas de coleta de dados (OLIVEIRA; DAÓLIO, 2007; SALOMÃO, 2017), a pesquisa etnográfica também foi experimentada de outras maneiras. Foi o caso da autoetnografia (BOSSLE, MOLINA NETO, 2009, p. 133), que surge como uma etnografia centrada nas experiências do próprio pesquisador no contexto em que atua. Em certo sentido, pode ser entendida como uma autonarrativa, isto é, o sujeito que pesquisa lida "com os próprios impulsos, sentimentos e emoções em relação ao objeto de pesquisa e sua própria cultura".

Diante desse cenário e encorajados pelas premissas e pressupostos teóricos das pesquisas pós-críticas em educação, a etnografia pós-crítica foi gestada em um contexto singular de investigação, com intenções específicas, em que assumimos simultaneamente a condição de professor e pesquisador da própria prática pedagógica inspirada nos pressupostos epistemológicos, didáticos e políticos da Educação Física cultural, também chamada currículo cultural da Educação Física (NEIRA, 2018; NEIRA; NUNES, 2020).

Assim, o presente artigo objetiva apresentar as contribuições da etnografia pós-crítica quando adotada em uma pesquisa educacional sobre a própria prática pedagógica. Para tanto, deslindaremos seus pressupostos teóricos, apresentaremos alguns aspectos que lhe são característicos, relataremos de forma breve uma experiência de pesquisa e, por fim, realizaremos apontamentos que podem servir de estímulo a futuros pesquisadores e pesquisadoras que pretendam investigar as próprias práticas pedagógicas.

\section{PRESSUPOSTOS DAS PESQUISAS PÓS-CRÍTICAS EM EDUCAÇÃO}

Na década de 1990, as discussões referentes à teorização pós-crítica passam a ocupar fortemente o campo educacional, principalmente nos estudos curriculares. Não demorou muito para que esse debate alcançasse as pesquisas educacionais. O levantamento feito por Paraíso (2004, 
2005) sobre trabalhos de caráter pós-crítico em currículo evidenciou as expansões e rupturas provocadas no campo.

De forma geral, as pesquisas pós-críticas, segundo Paraíso (2004, p. 286), não se apegam a “explicações universais, nem de totalidades, nem de completudes ou plenitudes", ao contrário, preferem as narrativas parciais de contextos locais, pois escapam das metanarrativas que ousam explicar todas as situações com base em conhecimentos tidos como universais.

Ao atuar nas particularidades de cada contexto, a ação da pesquisa pós-crítica educacional vai depender dos questionamentos feitos, das interrogações provocadas e dos problemas que surgem durante o percurso. O esforço é justamente pensar em outros "modos de pesquisar a partir do nosso objeto de estudo e do problema de pesquisa que formulamos” (PARAÍSO, 2014, p. 35).

Isso não significa descartar o que já se produziu sobre o objeto de estudo até o momento. Pensar em pesquisas de caráter pós-crítico é se ocupar do que já foi elaborado, seja qual for o campo teórico, para então, interrogar e problematizar os conhecimentos produzidos e os caminhos trilhados. Logo, pesquisadores e pesquisadoras que atuam sob a perspectiva pós-crítica ressignificam aquilo que já foi significado acerca do tema em questão, através de olhares diferentes daqueles que já foram lançados.

Paraíso (2014) explica que alguns elementos têm mobilizado pesquisadoras e pesquisadores na condução de suas investigações. Esses elementos não dizem respeito a etapas a serem seguidas, mas sim procedimentos comumente empregados pelas pesquisas pós-críticas na educação. Vejamos alguns deles.

Para adentrar ao universo que a pesquisa pós-crítica vem escrevendo, um elemento que precisamos considerar são as relações de poder. Torna-se imprescindível fazer uma análise da operação do poder no momento da investigação, como é exercido e deslocado nas relações entre os sujeitos, entre os sujeitos e o objeto de estudo e quais os efeitos gerados. Na teorização pós-crítica, o poder é compreendido a partir das contribuições foucaultianas, é visto como algo que não possui foco único, pois é exercido pelos sujeitos sobre a ação de outros sujeitos, ou seja, trata-se de um conjunto de ações sobre ações possíveis (FOUCAULT, 1995).

Ainda no rastro das contribuições foucaultianas, outro elemento importante às pesquisas educacionais pós-críticas é a função produtiva assumida pelos discursos, isto é, parte-se do pressuposto que a linguagem não apenas nomeia objetos e situações, mas produz aquilo que narra. Os discursos são compreendidos como práticas que formam sistematicamente os objetos que narram. Desse modo, as realidades investigadas e os problemas e resultados da pesquisa são construções discursivas ocorridas no interior das tramas da própria pesquisa. Pesquisadoras e 
pesquisadores pós-críticos, então, buscam estratégias de descrição e análise que possibilitem mostrar as relações de poder que impulsionaram os discursos investigados.

Ao trabalhar com uma possibilidade infinita de saberes, outro elemento que a pesquisa póscrítica busca trazer à ação investigativa são os atos de compor, decompor e recompor. Compõe-se um mapa com tudo aquilo que já foi dito sobre o objeto de estudo. Decompõe-se porque é preciso interrogar os significados construídos, de modo a possibilitar outras formas de pensar o objeto de estudo. Por fim, recompõe-se, porque a pesquisa necessita e exige uma invenção, a produção de um novo território, considerando novas ideias e modos de pensar.

A possibilidade de poetizar é mais um elemento para o trabalho com pesquisas educacionais pós-críticas. Significa inventar, artistar, criar novos olhares, estar aberto aos encontros gerados pela pesquisa para que algo novo seja produzido. Para poetizar na pesquisa em educação é necessário fazer rupturas com referenciais familiares, com conhecimentos consagrados. Essa é uma tarefa desafiadora porque "romper com as imagens de pensamento já conhecidas é por demais complexo, montar o novo, daquilo que trazemos de diferentes campos e com rigor, demanda coragem, ousadia, dinamicidade, abertura" (PARAÍSO, 2014, p. 42).

Outro elemento a se considerar nas pesquisas pós-críticas é a articulação de saberes e a bricolagem de métodos. Como já dito anteriormente, pesquisadoras e pesquisadores pós-críticos não se apegam a uma única teoria para explicar o fenômeno investigado e não possuem um único método a ser empregado. Pelo contrário, são utilizados todo e qualquer conhecimento e ferramentas metodológicas que servem aos estudos, de modo a encontrar caminhos e condições para que algo novo e diferente seja produzido.

Esse último elemento faz coro às premissas teóricas e políticas dos Estudos Culturais quando colocadas em ação na pesquisa educacional. Na sua vertente pós-estruturalista, os Estudos Culturais aproveitam qualquer campo teórico que seja necessário para produzir o conhecimento exigido. Conforme explicam Frow e Morris (2006, p. 329), a pesquisa educacional ancorada nos Estudos Culturais busca "utilizar cada vez mais técnicas de análise textual, empregar uma diversidade crescente de fontes, utilizar metodologias de forma mais eclética" de modo a trabalhar a complexa relação entre o pesquisador ou pesquisadora e a cultura investigada.

Em síntese, as teorias pós-críticas influenciaram o campo da pesquisa educacional a ponto de fazer com que pesquisadores e pesquisadoras evitem tornar-se reféns de métodos já conhecidos e aplicados à exaustão. Mais que nunca, o momento requer a busca de alternativas que escapem dos sistemas de pensamento que separam, classificam e fixam as verdades. Precisamos arriscar para criarmos outras possibilidades de pensar, outras maneiras de pesquisar. E as teorias pós-críticas certamente contribuem para isso. 


\section{ETNOGRAFIA PÓS-CRÍTICA}

Em nossa pesquisa, que objetivou investigar as significações atribuídas por estudantes sobre as próprias experiências com o currículo cultural da Educação Física, houve o acompanhamento de aulas, realização de entrevistas com estudantes e a análise de documentos pedagógicos. Sem maiores detalhes, poderíamos pensar que o emprego da etnografia estaria de bom tamanho. Entretanto, a pesquisa se delineou sob uma complexa relação entre pesquisador, sujeitos investigados e objeto de estudo, uma vez que atuamos como professor e pesquisador das turmas sob nossa responsabilidade.

Como docente, as aulas planejadas e desenvolvidas sofreram influências das reações e significações das crianças e jovens durante a pesquisa, e isso replicou diretamente nos dados produzidos como investigador. Desse modo, os e as estudantes, por assumirem uma posição fundamental no rumo das situações didáticas também ocuparam o mesmo lugar na pesquisa, enquanto nós, ao planejarmos certas atividades de ensino e realizarmos determinadas problematizações, também assumimos um papel importante no rumo das significações expressas pelos e pelas participantes e, consequentemente, na produção dos dados da pesquisa.

Nesse contexto singular em que a investigação ocorreu, compreendemos que a etnografia deveria ser redesenhada, ressignificada, isto é, que poderia ser vista sob o enfoque das teorias póscríticas. E assim o fizemos.

A etnografia pós-crítica pode ser concebida como uma ressignificação da etnografia. As demandas singulares da investigação nos encorajaram a pensá-la e adotá-la, devido ao caráter inventivo característico das pesquisas pós-críticas em educação (PARAÍSO, 2004, 2014). Contudo, seguindo o raciocínio da autora, as pesquisas pós-críticas em educação não descartam o que foi produzido e utilizado até o momento, logo, os conceitos caros à etnografia também foram considerados.

Resumidamente, compreendemos que a pesquisa etnográfica consiste no acompanhamento de processos. Acompanhar processos é começar pelo meio, é reconhecer que quando o etnógrafo ou etnógrafa entra no campo, há processos acontecendo, cabendo a ele ou ela abrir-se ao encontro deles. Idárraga (2014, p. 75) afirma que o pesquisador ou pesquisadora, para além de fazer meras descrições, deve dispor-se a estar e se entregar no local investigado, pois o "mais importante, à primeira vista, não é o resultado nem a conclusão, mas sim a trajetória, a experiência, o percurso". 
Por isso, observa a dinâmica, as interações sociais e se atenta ao processo de construção coletiva em torno do objeto de estudo no exato momento em que ocorrem as experiências.

Aliás, que fique claro que o etnógrafo ou etnógrafa precisa conhecer o ambiente investigado, seja ele qual for, "por dentro", sentir o clima, ver e participar dos detalhes, enfim se conectar à pesquisa. Isso significa que a presença constante na escola é imprescindível e, não somente, no acompanhamento das aulas. Muita coisa acontece antes e depois, ao lado, no outro dia ou no dia anterior. Tudo o que se diz ou se faz que influencia o objeto investigado interessa ao pesquisador ou pesquisadora. Reduzir a etnografia à observação das aulas é o mesmo que recortar o objeto de estudo, apreendendo somente um pedaço dele.

As contribuições pós-críticas à etnografia destacam o caráter produtivo da linguagem durante a pesquisa e a análise do exercício do poder entre os sujeitos do processo investigativo. A etnografia pós-crítica entende que os discursos produzidos pela investigação constroem o objeto sempre de maneira parcial. Em outras palavras, na concepção pós-crítica, a linguagem não faz a mediação entre o que vemos e o que pensamos, a realidade não vem antes da linguagem, mas sim, a linguagem constitui a realidade que é definida de uma ou outras formas, devido, justamente, às relações de poder. Desse modo, os sujeitos da investigação são efeitos das linguagens, dos discursos, do poder que é exercido, das representações e das significações que os produzem enquanto sujeitos (FROW; MORRIS, 2006).

No momento da ação, a etnógrafa ou etnógrafo ancorado na perspectiva pós-crítica permitese envolver no campo investigativo porque o que lá acontece não está pronto e definido, tampouco é algo dado e acabado. Está claro que, por vezes, o pesquisador ou pesquisadora é um membro da cultura investigada. Ele ou ela expõe suas dúvidas, mostra os caminhos trilhados e trabalha em cima dos limites de observação dessa perspectiva. Klein e Damico (2014) explicam que tamanho envolvimento faz com que a pesquisadora ou pesquisador seja surpreendido e modificado pela própria pesquisa, fazendo-o buscar reformulações constantes na produção de significados e no modo como os traduz. Uma etnografia ancorada na teorização pós-crítica cria uma transversalidade entre os sujeitos da investigação e o pesquisador ou pesquisadora e faz com que não sejam e nem atuem como meros informantes, mas como sujeitos produtores da pesquisa (DORNELLES, 2014).

A etnografia pós-crítica retrata a experiência da investigação tal e qual vivida em campo, de forma fragmentada, parcial e não enquanto o todo absoluto. Tyler (2008, p. 312) afirma que "esa experiencia deviene experiencia sólo em la escritura de la etnografia [...] Ninguna experiencia precedió a la etnografia. La experiencia es la etnografia”, ou seja, a pesquisa etnográfica pós-crítica não apenas descreve a experiência, mas sim, ela mesma torna-se a experiência. 
Enfim, a etnografia, quando influenciada pelas teorias pós-críticas, oferece o maior compromisso possível com a problemática da investigação. Isso porque escancara as relações existentes entre pesquisador ou pesquisadora e sujeitos investigados, afastando a ideia de que o envolvimento no ambiente da pesquisa "contamina" os dados. A etnografia pós-crítica reconhece que sua ação se situa historicamente, está constantemente em mudança e é afetada por posicionamentos políticos e ideológicos. Faz-se necessário, portanto, marcar a posição que ocupa, assumindo-a durante a prática investigativa.

\section{A ETNOGRAFIA PÓS-CRÍTICA EM CURSO: relato da pesquisa}

Com base nos pressupostos teórico-metodológicos que subsidiam a etnografia pós-crítica, a pesquisa aqui relatada objetivou investigar as significações atribuídas por estudantes do Ensino Fundamental à experiência com a Educação Física na perspectiva cultural. $\mathrm{O}$ acompanhamento das aulas ocorreu nos anos de 2015 e 2016. O emprego da etnografia pós-crítica permitiu observar principalmente as aulas de Educação Física, mas também atentamos aos intervalos entre as aulas e horários de entrada e saída. Os comentários, reivindicações, gestos, posturas e conversas dos e das estudantes foram documentados no diário de campo. Além disso, analisamos documentos referentes às aulas, tanto os oficiais, quanto o acervo de registros escritos e iconográficos elaborados pelas crianças e jovens. Também realizamos entrevistas com aquelas e aqueles que se voluntariaram quando as turmas foram consultadas abertamente.

Os dados produzidos pela etnografia pós-crítica foram analisados a partir da análise cultural (COIRO-MORAES, 2015; WORTMANN, 2007), com o intento de decodificar os significados produzidos durante a investigação. De acordo com Coiro-Moraes (2015), a análise cultural assume uma dimensão política, a fim de integrar elementos de ordem econômica, social e cultural nas análises empreendidas. Para isso, envolve formas amplas de interpretação caracterizadas pelo diálogo com variados campos do conhecimento.

A análise cultural atua para compreender como as práticas culturais são vividas e experimentadas pelos sujeitos, partindo do sentimento real da experiência coletiva. Por conseguinte, compartilha o compromisso de examinar práticas culturais e seu envolvimento no interior das relações de poder, tratando de observar as negociações ocorridas no cotidiano dos sujeitos e os efeitos em suas vidas (WORTMANN, 2007).

Consideramos importante explicar brevemente a prática político-pedagógica do currículo cultural da Educação Física. Ao empenhar-se na afirmação das diferenças, propõe a tematização das 
práticas corporais, ou seja, busca realizar uma compreensão profunda das práticas corporais em uma realidade social, cultural e política, de modo a problematizar os significados que lhe são atribuídos, bem como aos seus praticantes. O currículo cultural possibilita que estudantes e docentes reconheçam o universo cultural corporal à sua volta e utilizem todo e qualquer conhecimento que auxilie na leitura da ocorrência social e na produção da brincadeira, dança, luta, ginástica ou esporte tematizados (NEIRA, 2008).

Na prática pedagógica, ao longo da tematização, estudantes vivenciam a prática corporal, analisam o contexto histórico e as forças que atuaram para que fosse representada de determinada maneira, interpretam sua intenção política no cenário social, acessam outros conhecimentos que contribuem para a sua compreensão, entre tantas outras situações.

Com relação à pesquisa realizada, quando empregamos a etnografia pós-crítica, concebemos que a realidade investigada, qual seja, as aulas de Educação Física culturalmente orientadas desenvolvidas em uma escola municipal situada no extremo leste da cidade de São Paulo, pode ser tomada como uma produção discursiva elaborada durante a experiência. Os sujeitos envolvidos produziram aquilo que foi dito e vivido naquele momento (FROW; MORRIS, 2006), e que fatalmente, forneceram os rumos que conduziram os trabalhos pedagógico e investigativo.

Um primeiro aspecto que nos ajuda a compreender o modo como os e as estudantes concebem o currículo cultural da Educação Física é a importância que conferem aos momentos de diálogo proporcionados durante as aulas. O diálogo não deve ser entendido como uma doação ou imposição de ideias e pensamentos de uns para outros, mas sim, como um momento de encontro onde os sujeitos disputam modos de pensar as realidades que vivem, ressignificando-as conforme suas leituras.

Quando questionadas, duas estudantes afirmaram que o diálogo é algo importante nas aulas de Educação Física, porque "tipo, se você escolhe um tema que, umas pessoas gostam e outras não gostam, e tem umas também que não concordam com aquele tema, é bom discutir com a sala porque aí a sala entra em acordo com um tema só" (Lívia ${ }^{1}$ ), como também “porque é aí que você dá mais atenção pro assunto. Porque, tipo, você fica lá sentado na sala e fica: ah, e agora? Só ouvindo o professor falar o tempo todo. É legal porque você tem a sua hora de falar sua opinião" (Isadora).

Ao colocarmos em ação a prática dialógica no currículo cultural da Educação Física, reconhecemos as vozes das crianças e jovens porque sabemos que o diálogo dá contornos às aulas e desestabiliza as certezas trazidas pelos sujeitos. É por meio do diálogo que os sujeitos analisam as práticas corporais e as compreendem no emaranhado da teia social. De acordo com Neira (2019), ao

\footnotetext{
${ }^{1}$ Todos os nomes utilizados são fictícios.
} 
organizarmos situações em que os e as estudantes falem a respeito das práticas corporais, emitam seus posicionamentos acerca dos acontecimentos nas aulas, positivando algumas ações ou sugerindo alterações, a aula de Educação Física se torna um ambiente propício ao intercâmbio de significados e à afirmação das diferenças.

O ambiente dialógico propiciado pelas aulas culturalmente orientadas foi fortalecido na pesquisa a partir do momento em que a etnografia pós-crítica permitiu que nos envolvêssemos completamente na investigação a ponto de replanejarmos as aulas e, consequentemente, os rumos da pesquisa, a partir de posicionamentos discentes. Em um dos episódios registrados no Diário de Campo em 13/08/2015, um grupo de meninas questionou o motivo de somente escutar os meninos no momento da definição da prática corporal a ser tematizada. Em outras palavras, as meninas alertaram-nos para que atentasse às práticas corporais mais presentes no universo feminino. $\mathrm{O}$ resultado dessa intervenção levou-nos a redirecionar o tema de estudo para a ginástica rítmica, com a dupla intenção de democratizar as experiências pedagógicas e promover a justiça curricular, princípio ético-político do currículo cultural por meio do qual se busca facilitar o acesso a significados produzidos por outros grupos sociais.

Outra significação importante realizada por estudantes com relação às aulas foram os momentos em que planejamos ocasiões para o compartilhamento de saberes de companheiros e companheiras de sala e representantes das práticas corporais tematizadas. Durante a tematização do skate e dos patins, as crianças, para além de assistir vídeos, vivenciar corporalmente, ler textos que retratavam o posicionamento de praticantes, disponibilizar notícias e debater questões que apresentamos a partir das falas das turmas, também conversaram com uma skatista e um aluno de outra turma praticante de skate, escutaram e discutiram com os e as colegas sobre o skate e os patins, e entrevistaram uma ex-patinadora. Convidados e convidadas a se pronunciar sobre essas situações, assim se manifestaram:

Kevin: Então, e acho que a entrevista, com aquilo que ela falou, deu pra aprender um pouco sobre os patins. Deu pra aprender como manusear e andar.

Prof.: Vocês acharam importante ela vir?

Leonardo: Sim. Ela ensinou a andar de costas.

Ana Lucia: Ela ensinou também como fazer para parar nos patins.

Kauan: Ensinou muito mais que o professor (risos de todas).

Gisele: É porque ela entende mais do assunto. (ENTREVISTA 09).

Decerto, a convidada tem muito mais a discutir com as crianças que nós, pois é possuidora de uma vasta experiência nos patins. Mas isso não nos colocou numa situação passível e irrelevante, pois compreendemos que o professor ou professora que atua na perspectiva cultural planeja 
situações didáticas que proporcionam o contato com conhecimentos e pontos de vista que contribuam para qualificar a leitura da ocorrência social da prática corporal. Esse processo será prejudicado caso a experiência pedagógica permaneça restrita aos saberes do professor ou professora ou àqueles disponibilizados pelos meios de comunicação. Oliveira Junior (2017) percebeu que muitas vezes os significados acessados pelas mídias reforçam posturas preconceituosas ou colocam os sujeitos na condição de meros consumidores.

O momento de compartilhamento de conhecimentos com a participação das pessoas cujas histórias de vida se ligam à prática corporal tematizada não é privilégio de pessoas adultas. Inclui crianças pequenas, jovens e colegas de sala que muito podem contribuir com o tema. $\mathrm{Na}$ tematização das brincadeiras, as próprias crianças foram responsáveis pelas explicações do seu funcionamento e características. A cada aula, um grupo de estudantes era convidado a apresentar sua brincadeira à turma e, no coletivo, discutiam sobre possibilidades de adequação e modificação. Quando questionados sobre a experiência, Kevin e Leonardo foram enfáticos ao afirmarem que preferiram quando os colegas de sala explicaram as brincadeiras: "Foi melhor a gente explicar, porque a gente sabe um pouco mais. Os adultos não gostam muito das brincadeiras das crianças, não conhecem muito".

Em ambas as tematizações, as crianças destacam a participação de outras pessoas, geralmente representantes das práticas corporais. Torna-se relevante que os enunciados emitidos por participantes das práticas corporais, sejam crianças, jovens, adultos ou idosos sejam ouvidos e problematizados. Afinal, ninguém melhor do que os próprios sujeitos para contribuírem com os saberes ancorados socialmente (NEVES, 2018).

Outro elemento percebido durante a investigação sobre as aulas de Educação Física na perspectiva cultural foi o fato de estudantes identificarem a existência de formas variadas de participar das aulas para além daquelas que preconizam a vivência corporal propriamente dita. $\mathrm{O}$ registro a seguir retrata essa observação.

Durante a vivência da luta de jiu-jitsu, dois alunos que acompanhavam a luta de outros dois colegas começaram a orientá-los sobre as técnicas que poderiam realizar ou as estratégias que poderiam adotar para que um imobilizasse o outro. Foi interessante perceber que esses alunos não foram observados em momentos de vivência e que conheciam pouco sobre a luta no início das aulas. Porém, estavam atentos às nossas explicações e às discussões com os colegas (DIÁRIO DE CAMPO, 28/06/2016).

Foi possível inferir que estudantes compreenderam que as aulas de Educação Física não se limitam à execução motora dos esportes, danças, lutas, ginásticas e brincadeiras. Isso demonstrou 
que se apropriam dos conhecimentos referentes às práticas corporais de diferentes maneiras, cada qual a partir de suas leituras e experiências. Em outro momento, quando questionada sobre a tematização da dança sertaneja, Patrícia seguiu a mesma ideia: "a gente interagiu bastante. A gente dançou, a gente pesquisou, a gente ouviu as músicas, a gente viu os vídeos das pessoas dançando”.

Reconhecemos que os gestos e técnicas corporais são elementos constitutivos das práticas corporais. É o que confere materialidade aos esportes, danças, lutas, brincadeiras e ginásticas. Sem eles não há qualquer possibilidade de significação. Entretanto, os resultados evidenciam que não é somente por meio da prática motora que estudantes aprendem sobre as práticas corporais. Reiteramos que a perspectiva cultural da Educação Física não nega a vivência corporal, apenas retira a sua exclusividade e abre portas para que outras formas de participação discente aconteçam, desde que sejam momentos profícuos para a análise e compreensão das práticas corporais.

A adoção da etnografia pós-crítica na pesquisa também permitiu observar alguns efeitos e marcas que o currículo cultural da Educação Física gerou nas crianças e jovens. Uma dessas marcas foi a postura problematizadora que assumiram durante as tematizações.

Ao terminar o período das aulas hoje, a mãe do aluno Daniel foi à escola para conversar com a coordenadora pedagógica sobre uma possível matrícula dele em uma turma de recuperação paralela. Quando ele nos viu pelos corredores, nos apresentou para sua mãe como o seu professor de Educação Física. Ela, então, contou que ele queria que lhe comprasse um skate, devido ao fato dele estar aprendendo sobre essa prática corporal nas aulas de Educação Física. Porém, desaprovando tal situação disse: 'eu já disse pra ele que isso é coisa de maloqueiro'. Antes que eu falasse algo, o Daniel argumentou para a sua mãe: 'Isso não tem nada a ver mãe. Até os velhinhos andam de skate e eles não são maloqueiros' (DIÁRIO DE CAMPO, 16/09/2015).

Entre os efeitos do currículo cultural observados, destacamos o momento em que a aluna Raiane retomou as discussões sobre gênero engendradas ao longo da tematização da ginástica rítmica para argumentar em defesa do reconhecimento feminino nas práticas corporais (DIÁRIO DE CAMPO, 18/08/2016); quando um grupo de meninas reagiu energicamente à ideia sugerida pelos meninos que o tempo de vivência do futebol delas fosse menor (DIÁRIO DE CAMPO, 29/06/2016); e quando um estudante rebateu energicamente o interesse de seus colegas de turma que queriam apenas jogar futebol nas aulas: "tem tanta coisa pra gente estudar, porque os mesmos só pedem futebol? Não será futebol agora”. (DIÁRIO DE CAMPO, 18/05/2016).

Essas manifestações podem ser atribuídas a longas e intensas problematizações realizadas durante os dois anos de experiência com a proposta. As posturas observadas nesses registros, por mais simples e corriqueiras que possam parecer, revelam a produção de novos significados acerca 
da Educação Física, demonstrando que a perspectiva cultural atuou para que certezas, antes intocadas na área, fossem desestabilizadas (OLIVEIRA JUNIOR, 2017).

Por ora, os resultados que pontuamos evidenciam significações importantes graças à etnografia pós-crítica, uma perspectiva teórico-metodológica que permitiu relatar a nossa forte ligação com os sujeitos da investigação e com o objeto de estudo. Sem isso, a pesquisa correria o risco de manter-se na visão exclusiva dos seus autores, como se fossem os únicos responsáveis pela investigação realizada.

A etnografia pós-crítica buscou atentar para as significações expressas pelos sujeitos enquanto experiência vivida com o currículo cultural de Educação Física, para além da simples descrição dos fatos ocorridos. Logo, não se pretendeu fazer revelações ou apresentar descobertas acerca do objeto de estudo, nem tampouco solucionar qualquer entrave eventualmente identificado.

\section{ALGUMAS CONSIDERAÇÕES}

As situações narradas evidenciaram que a etnografia pós-crítica se atentou para as representações expressas pelos sujeitos enquanto significações acessadas nas aulas de Educação Física na perspectiva cultural e não como simples descrições fora de contexto. Na visão de Paraíso (2014), esse modo de pesquisar não pretende denunciar ou desocultar algo que esteja velado, o esforço é para que aqueles aspectos que comumente passam despercebidos possam ser questionados e problematizados para que novas significações sejam postas em circulação. É justamente nesse ponto que residiu a dimensão política da análise cultural aliada à etnografia pós-crítica.

A etnografia pós-crítica revela-se uma importante ferramenta quando considera a linguagem enquanto dispositivo de construção da realidade investigada; não despreza as relações do poder que perpassam o contexto da pesquisa; contraria a "neutralidade científica"; pondera a participação dos sujeitos enquanto produtores da pesquisa e ecoa os efeitos vividos pelos e pelas participantes durante o processo.

Essa perspectiva teórico-metodológica escancara as condições e relações que influenciaram a produção e legitimação de verdades. A etnografia pós-crítica reconhece os sujeitos do estudo, não como meros informantes, mas como produtores e produtoras da pesquisa, como também, permite grande envolvimento do pesquisador ou pesquisadora na cultura investigada.

Isso pode estimular a sua adoção por quem deseja investigar a própria prática pedagógica. Contudo, ressalvamos que a etnografia pós-crítica deve atender às demandas específicas do contexto investigado e moldar-se aos contornos singulares de cada pesquisa. Então, não se trata 
apenas em replicar essa perspectiva teórico-metodológica indiscriminadamente. Pelo contrário, é importante ressignificá-la sempre que o contexto pesquisado exigir.

Enfim, diante do atual cenário da pesquisa educacional não podemos mais fechar os olhos para a influência do discurso pós-crítico na produção de conhecimentos. Mais que isso, é fundamental que esse campo teórico encoraje outros pesquisadores e pesquisadoras na invenção e ressignificação de ferramentas metodológicas condizentes aos contextos de cada pesquisa e seus objetos de estudo. Nestes tempos sombrios em que vivemos, vale a pena todo esforço que puder ser feito para escapar dos sistemas de pensamento que engessam significados e fixam verdades.

\section{REFERÊNCIAS}

BALESTRIN, Patrícia Abel; SOARES, Rosângela. "Etnografia de tela": uma aposta metodológica. In: MEYER, Dagmar Estermann; PARAISO, Marlucy Alves (Orgs.). Metodologias de pesquisas pós-críticas em educação. $2^{a}$ ed. Belo Horizonte: Mazza, 2014. p. 89-111.

BOSSLE, Fabiano; MOLINA NETO, Vicente. No "olho do furacão": uma autoetnografia em uma escola da rede municipal de ensino de Porto Alegre. Rev. Bras. Cienc. Esporte, Campinas, v. 31, n. 1, p. 131-146, set. 2009.

BUENO, Belmira Oliveira. Entre a antropologia e a história: uma perspectiva para a etnografia educacional. Perspectiva, Florianópolis, v. 25, n. 2, p. 471-501, jul./dez. 2007.

COIRO-MORAES, Ana Luiza. A análise cultural. In: COMPÓS, XXIV, 2015. Brasília. Disponível em https://proceedings.science/compos-2015/papers/a-analise-cultural Acesso em: 25 jul. 2021.

DORNELLES, Leni Vieira. Sobre raça, racismo, negritude e beleza: o que as crianças têm a dizer sobre esse tema? In: GHANEN, Elie; NEIRA, Marcos Garcia. Educação e diversidade no Brasil: ensaios e práticas. Araraquara: Junqueira\&Marin, 2014.

FOUCAULT, Michel. O sujeito e o poder. In: DREYFUS, Hubert; RABINOW, Paul. Michel Foucault: uma trajetória filosófica - para além do estruturalismo e da hermenêutica. São Paulo: Forense Universitária, 1995. p. 231-249.

FROW, John; MORRIS, Meaghan. Estudos Culturais. In: DENZIN, Norman; LINCOLN, Yvonna (Orgs.). O planejamento da pesquisa qualitativa: teorias e abordagens. Porto Alegre: Artmed, 2006. p. 315-344.

GEERTZ, Clifford. A interpretação das culturas. Rio de Janeiro: Guanabara Koogan, 1989.

IDÁRRAGA, Maria Rossi. Sobre um olhar etnográfico como gesto pedagógico. In: MARTINS, Fabiana Fernandes Ribeiro; VARGAS NETTO, Maria Jacintha; KOHAN, Walter Omar (Orgs.). Encontrar escola: o ato educativo e a experiência da pesquisa em educação. Rio de Janeiro: Lamparina, FAPERJ, 2014. p. 73-81.

KLEIN, Carin; DAMICO, José. O uso da etnografia pós-moderna para a investigação de políticas públicas de inclusão social. In: MEYER, Dagmar Estermann; PARAISO, Marlucy Alves (Orgs.). Metodologias de pesquisas pós-críticas em educação. $2^{\mathrm{a}}$ ed. Belo Horizonte: Mazza, 2014.p. 65-87. 
NEIRA, Marcos Garcia. A Educação Física em contextos multiculturais: concepções docentes acerca da própria prática pedagógica. Currículo sem Fronteiras, v. 8, n. 2, pp.39-54, jul./dez., 2008.

NEIRA, Marcos Garcia. O currículo cultural da Educação Física: pressupostos, princípios e orientações didáticas. Revista e-Curriculum, São Paulo, v.16, n.1, p. 4 - 28 jan./mar.2018.

NEIRA, Marcos Garcia. Educação física cultural: inspiração e prática pedagógica. $2^{\mathrm{a}}$ ed. Jundiaí: Paco, 2019.

NEIRA, Marcos Garcia; NUNES, Mário Luiz Ferrari. As dimensões política, epistemológica e pedagógica do currículo cultural da Educação Física. In: BOSSLE, Fabiano; ATHAYDE, Pedro; LARA, Larissa. Educação Física escolar. Natal: EDUFRN, 2020. p. 25-43.

NEVES, Marcos Ribeiro. O currículo cultural da Educação Física em ação: efeitos nas representações culturais dos estudantes sobre as práticas corporais e seus representantes. 2018. 198 f. Dissertação (Mestrado em Educação). Universidade de São Paulo. Faculdade de Educação. São Paulo, 2018.

OLIVEIRA, Amurabi. Por que etnografia no sentido estrito e não estudos do tipo etnográfico em educação? Revista da FAEEBA - Educação e Contemporaneidade, Salvador, v. 22, n. 40, p. 69-81, jul/dez. 2013.

OLIVEIRA, Rogério Cruz; DAOLIO, Jocimar. Pesquisa etnográfica em Educação Física: uma (re)leitura possível. Revista Brasileira de Ciência e Movimento, Brasília, 15(1), p. 137-143, 2007.

OLIVEIRA JUNIOR, Jorge Luiz. Significações sobre o currículo cultural da Educação Física: cenas de uma escola municipal paulistana. 2017. 156 f. Dissertação (Mestrado em Educação). Universidade de São Paulo. Faculdade de Educação. São Paulo, 2017.

PARAISO, Marlucy Alves. Metodologias de pesquisas pós-críticas em educação e currículo: trajetórias, pressupostos, procedimentos e estratégias analíticas. In: MEYER, Dagmar Estermann; PARAISO, Marlucy Alves (Orgs.). Metodologias de pesquisas pós-críticas em educação. $2^{a}$ ed. Belo Horizonte: Mazza, 2014. p. $25-47$.

PARAISO, Marlucy Alves. Currículo-Mapa: linhas e traçados das pesquisas pós-críticas sobre currículo no Brasil. Educação \& Realidade, Porto Alegre, 30(1), p. 67-82, jan/jun. 2005.

PARAISO, Marlucy Alves. Pesquisas pós-críticas em educação no Brasil: esboço de um mapa. Cadernos de Pesquisa, São Paulo, v. 34, n. 122, p. 283-303, maio/ago. 2004.

PEIRANO, Mariza. Etnografia não é método. Horizontes Antropológicos, Porto Alegre, ano 20, n. 42, p. 377-391, jul/dez. 2014.

SALES, Shirlei Rezende. Etnografia+netnografia+análise do discurso: articulações metodológicas para pesquisar em educação. In: MEYER, Dagmar Estermann; PARAISO, Marlucy Alves (Orgs.). Metodologias de pesquisas pós-críticas em educação. $2^{a}$ ed. Belo Horizonte: Mazza, 2014. p. 113-134.

SALOMÃO, Alexandre França. Pesquisas etnográficas em educação física escolar: um balanço de dissertações e teses. 2017. 152 f. Tese (Doutorado em Educação). Faculdade de Educação. Universidade de São Paulo. São Paulo: 2017.

TYLER, Stephen. La etnografía posmoderna: de documento de lo oculto a documento oculto. In: GEERTZ, Clifford; CLIFFORD, James (Orgs.). El surgimiento de la antropologia posmoderna. Barcelona: Gedisa, 2008. p. 297-313. 
WORTMANN, Maria Lucia Castagna. Análises culturais - um modo de lidar com histórias que interessam à educação. In: COSTA, Marisa Vorraber (Org.). Caminhos investigativos II: outros modos de pensar e fazer pesquisa em educação. Rio de Janeiro: Lamparina, 2002. p. 71-90.

\section{NOTAS DE AUTOR}

\section{AGRADECIMENTOS}

Estudantes participantes da pesquisa.

CONTRIBUIÇÃO DE AUTORIA - Não se aplica.

FINANCIAMENTO - Não se aplica.

CONSENTIMENTO DE USO DE IMAGEM - Não se aplica.

APROVAÇÃo DE COMITÊ DE ÉTICA EM PESQUISA - Não se aplica.

CONFLITO DE INTERESSES - Não se aplica.

\section{LICENÇA DE USO}

Os autores cedem à Motrivivência - ISSN 2175-8042 os direitos exclusivos de primeira publicação, com o trabalho simultaneamente licenciado sob a Licença Creative Commons Attribution Non-Comercial ShareAlike (CC BY-NC SA) 4.0 International. Esta licença permite que terceiros remixem, adaptem e criem a partir do trabalho publicado, desde que para fins não comerciais, atribuindo o devido crédito de autoria e publicação inicial neste periódico desde que adotem a mesma licença, compartilhar igual. Os autores têm autorização para assumir contratos adicionais separadamente, para distribuição não exclusiva da versão do trabalho publicada neste periódico (ex.: publicar em repositório institucional, em site pessoal, publicar uma tradução, ou como capítulo de livro), com reconhecimento de autoria e publicação inicial neste periódico, desde que para fins não comerciais e compartilhar com a mesma licença.

\section{PUBLISHER}

Universidade Federal de Santa Catarina. Programa de Pós-Graduação em Educação Física. LaboMídia - Laboratório e Observatório da Mídia Esportiva. Publicado no Portal de Periódicos UFSC. As ideias expressadas neste artigo são de responsabilidade de seus autores, não representando, necessariamente, a opinião dos editores ou da universidade.

\section{EDITORES}

Mauricio Roberto da Silva, Giovani De Lorenzi Pires, Rogério Santos Pereira.

\section{EDITOR DE SEÇÃO}

Silvan Menezes dos Santos

\section{REVISÃO DO MANUSCRITO E METADADOS}

João Caetano Prates Rocha; Keli Barreto Santos; Juliana Rosário.

\section{HISTÓRICO}

Recebido em: 02 agosto 2021

Aprovado em: 05 outubro 2021 